\title{
Above 8GHz Static T-Flip-Flop Operation using FT=22.9GHz GaAs MESFETs
}

\author{
Riishøj, J; Danielsen, Per Lander
}

Published in:

Proceedings of the 22nd European Microwave Conference

Link to article, DOI:

10.1109/EUMA.1992.335686

Publication date:

1992

Document Version

Publisher's PDF, also known as Version of record

Link back to DTU Orbit

Citation (APA):

Riishøj, J., \& Danielsen, P. L. (1992). Above 8GHz Static T-Flip-Flop Operation using FT=22.9GHz GaAs

MESFETs. In Proceedings of the 22nd European Microwave Conference (Vol. Volume 1, pp. 313-317). IEEE. https://doi.org/10.1109/EUMA.1992.335686

\section{General rights}

Copyright and moral rights for the publications made accessible in the public portal are retained by the authors and/or other copyright owners and it is a condition of accessing publications that users recognise and abide by the legal requirements associated with these rights.

- Users may download and print one copy of any publication from the public portal for the purpose of private study or research.

- You may not further distribute the material or use it for any profit-making activity or commercial gain

- You may freely distribute the URL identifying the publication in the public portal 


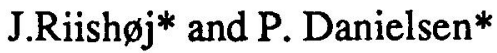

\section{ABSTRACT}

Abstract: A static SCFL Toggle Flip-Flop GaAs IC having maximum operating frequency of $\mathrm{F}_{\text {div }}=8.25 \mathrm{GHz}$ has been designed using a commercially available GaAs MESFET foundry service. The average $F_{t}$ for the present wafer is $F_{t}=22.9 \mathrm{GHz}$ giving a very high $F_{\text {div }} / F_{t}$-ratio of $\mathrm{F}_{\operatorname{div}} / \mathrm{F}_{\mathrm{t}}=0.36$. In addition output voltage transition times of $\mathrm{T}_{\mathrm{t}}(20 \%-80 \%)=35 \mathrm{ps}$ are obtained by implementation of a novel output driver design.

\section{MOTIVATION}

Recently there has been a dramatic progress in the development of ultrahigh-speed frequency dividers, thus maximum frequencies of operation of above $20 \mathrm{GHz}$ have been reported. These high performance devices are based on very advanced transistors, such as very short gate SAINT MESFETs (1), HEMTs (2) or HBTs (3). There has hence been a rather intense publishing activity regarding high divider speed obtained through new or refinement of existing processes. We do not have access to such advanced transistors mentioned above but are restricted to use commercially available foundry services. Therefore our approach has been to get maximum performance from the given MESFET process through circuit design. In order to compare with elsewhere reported divider performance we use the $\mathrm{F}_{\text {div }} / \mathrm{F}_{\mathrm{t}}$-ratio as a figure of merit of, how well a process is utilized. In Table 1 is shown a list of reported performance of static MESFET frequency dividers covering different authors (processes) over the past 14 years, and a grouping in the $F_{\text {div }} / F_{t}$ ratio of $0.30<F_{\text {div }} / F_{t}<0.33$ seems to be the case.

\begin{tabular}{|c|c|c|c|c|c|}
\hline$F_{f}$ & $F_{\text {div }}$ & $F_{\text {div }} / F_{f}$ & Year & $L_{g}$ & Author \\
\hline $15 \mathrm{GHz}$ & $4.5 \mathrm{GHz}$ & 0.30 & 1977 & $1.00 \mu \mathrm{m}$ & HP \\
\hline $15 \mathrm{GHz}$ & $5.0 \mathrm{GHz}$ & 0.33 & 1982 & $1.00 \mu \mathrm{m}$ & HP \\
\hline $23 \mathrm{GHz}$ & $7.5 \mathrm{GHz}$ & 0.33 & 1985 & $0.55 \mu \mathrm{m}$ & NTT \\
\hline $60 \mathrm{GHz}$ & $17.9 \mathrm{GHz}$ & 0.30 & 1986 & $0.20 \mu \mathrm{m}$ & HRL \\
\hline $35 \mathrm{GHz}$ & $11.0 \mathrm{GHz}$ & 0.31 & 1986 & $0.50 \mu \mathrm{m}$ & NTT \\
\hline $32 \mathrm{GHz}$ & $10.2 \mathrm{GHz}$ & 0.32 & 1988 & $0.40 \mu \mathrm{m}$ & NTT \\
\hline $49 \mathrm{GHz}$ & $16.0 \mathrm{GHz}$ & 0.33 & 1989 & $0.50 \mu \mathrm{m}$ & OKI \\
\hline $74.3 \mathrm{GHz}$ & $26.8 \mathrm{GHz}$ & 0.36 & 1989 & $0.15 \mu \mathrm{m}$ & NTT \\
\hline $22.9 \mathrm{GHz}$ & $8.25 \mathrm{GHz}$ & 0.36 & 1991 & $0.50 \mu \mathrm{m}$ & CBT \\
\hline
\end{tabular}

Table 1: Reported performance of static dividers based on GaAs MESFETs.

\section{DEVICE CHARACTERISTICS}

We have used Anadigics GaAs foundry service. They offer a $0.5 \mu \mathrm{m}$ gate length MESFET process. According to the PCM data for our wafer the MESFETs have a pinch-off voltage of $V_{p}=-0.8 \mathrm{~V}$, an ac transconductance of $\mathrm{G}_{\mathrm{m}}=189 \mathrm{mS} / \mathrm{mm}$, a saturation current of $I_{\mathrm{dss}}=140 \mathrm{~mA} / \mathrm{mm}$ and an average unity current gain frequency of $F_{t}=22.9 \mathrm{GHz}$. $F_{t}$ is calculated as $F_{t}=G_{m} / 2 \pi C_{g s}$ at $V_{d s}=2.5 V$ and $V_{g s}=0 V$.

* Center for Broadband Telecommunications (CBT)

Technical University of Denmark, Building 348

DK-2800 Lyngby, Denmark. 


\section{4-PHASE GENERATOR}

Designers of e.g. high-speed multiplexers and demultiplexers may need 4 timing signals at half the clock rate shifted $0,90,180$ and 270 degrees, respectively, instead of just a single signal at half the clock rate (4)(5). This lead to the divider configuration shown in Fig.1, where we use a Master-Slave D-Flip-Flop (MS D-FF) with the usual feed-back connections and take M,S and the corresponding complementary signals as output signals thus generating the desired 4 timing signals.

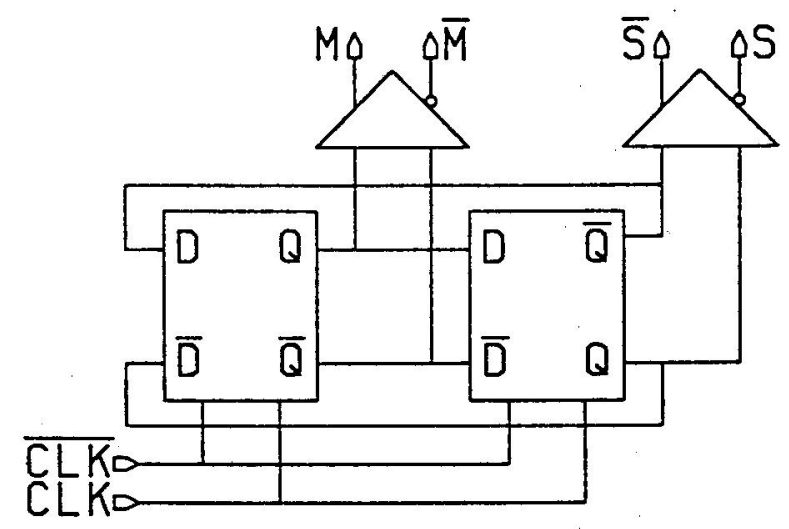

Fig 1: $\quad 1 / 2$ frequency divider configuration

\section{SCFL 1/2 FREQUENCY DIVIDER}

Both the master and the slave latch are realized using the well known SCFL two-level logic structure shown in Fig.2. Gate width scaling factors are chosen in such a manner, that all FETs are kept in good biasing conditions during the full logic swing, that is, switching FETs are operating near the peaking in the unity current gain frequency $F_{t}$ during switching, and the source follower input FETs are operating near the peaking in the transconductance $\mathrm{G}_{\mathrm{m}}$.

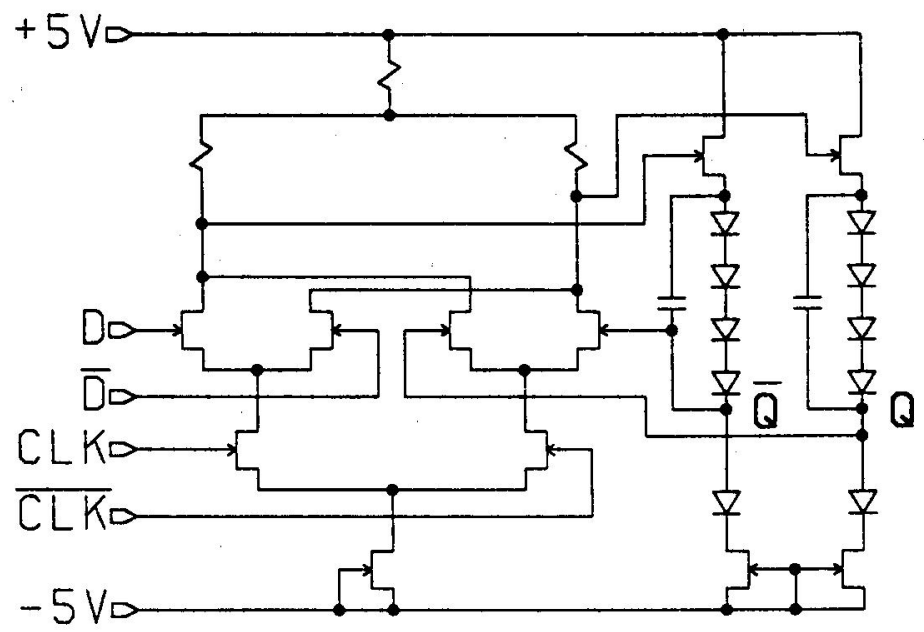

Fig 2: SCFL latch configuration used for both master and slave.

\section{NOVEL OUTPUT DRIVER DESIGN}

In order to achieve short rise and fall times at the output ports we have applied open drain outputs, which is commonly seen for devices operating at or above 5Gbit/s (6)(7). In addition we suggest this differential output stage to be driven by the differential push-pull bufferlamplifier shown in Fig.3. By using this output stage we have achieved very short transition times. 


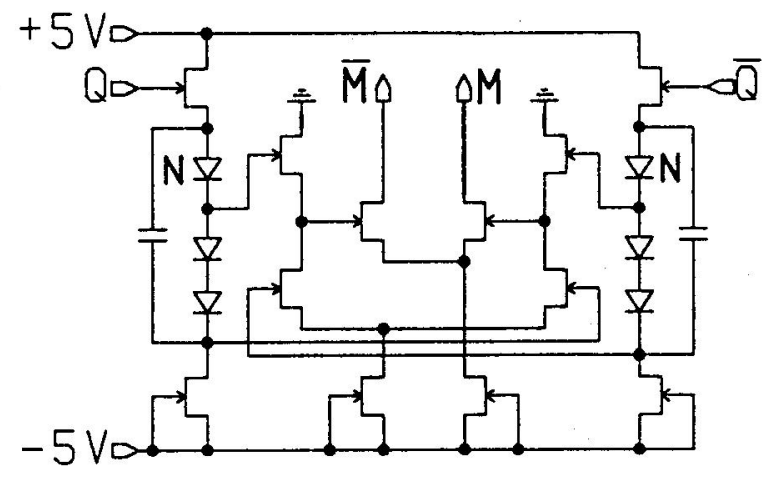

Fig 3: Differential push-pull output driver. $Q$ and $M$ represent input and output signals, respectively.

\section{MEASURED CIRCUIT PERFORMANCE}

Circuit performance was measured using a Cascade Microtech probe station. The dual phase input clock signals were generated using an HP microwave generator, a power splitter and a variable delay line. Output signals were monitored on a HP 4 channel sampling oscilloscope and a spectrum analyzer. A maximum toggle frequency of $8.25 \mathrm{GHz}$ was obtained at a power dissipation of $740 \mathrm{~mW}$ and an output voltage swing of $480 \mathrm{mV}$. The corresponding response monitored by a spectrum analyzer is shown in Fig. 4 At toggle frequencies above $7.5 \mathrm{GHz}$ the output signal duty cycle drifts rapidly away from $50 \%$, and the output voltage swing and input sensitivity are decreasing, Fig.5, thus adding the requirement for filtering and amplification at clock frequencies above $7.5 \mathrm{GHz}$ for most digital applications. However, at clock frequencies below $7.5 \mathrm{GHz}$, e.g. at $5 \mathrm{GHz}$ as shown in Fig.6, square-wave like outputs are generated having near $50 \%$ duty cycle, app. $800 \mathrm{mV}$ amplitude $(\mathrm{VOH}=0 \mathrm{~V})$ and very short transition times, Table 2.

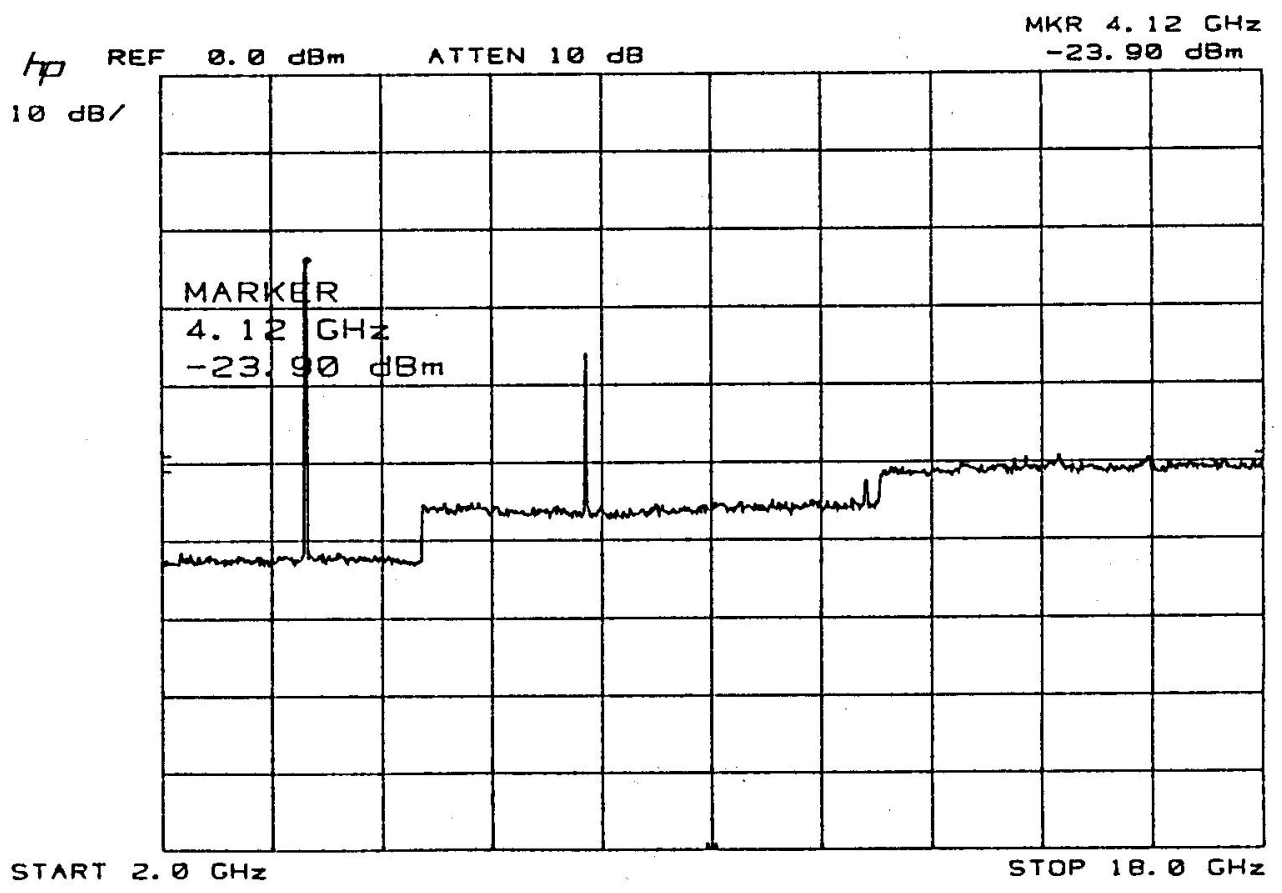

Fig 4: $\quad$ MS-TFF output measured by spectrum analyzer when operating at the maximum input frequency of $8.25 \mathrm{GHz}$. 


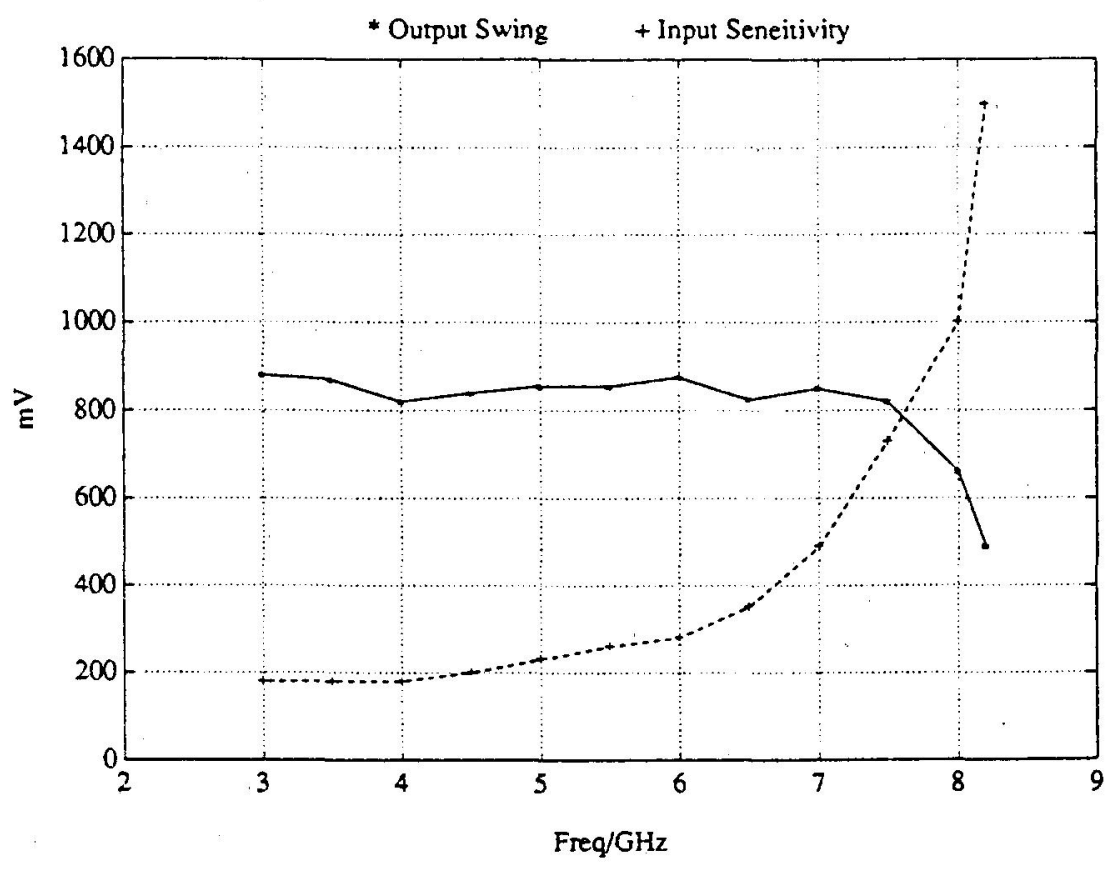

Fig 5: Input sensitivity (dashed line) and output voltage swing (solid line) as function of input clock frequency.

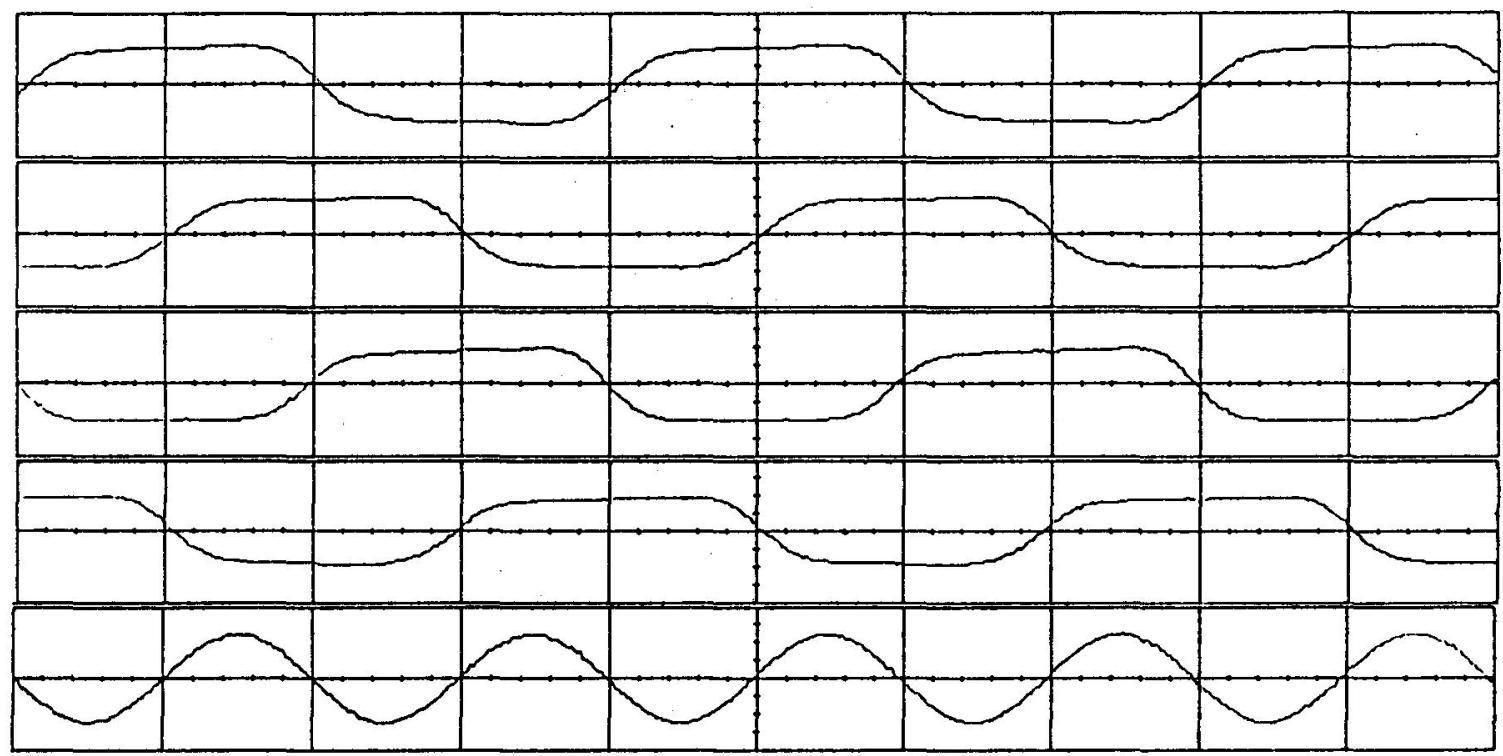

Fig 6: Measured Output signals M,S,NM,NS and corresponding input clock wave-forms when operating on a $5 \mathrm{GHz}$ clock. Vertical: $1 \mathrm{~V} / \mathrm{div}$ and Horizontal: $20 \mathrm{ps} / \mathrm{div}$.

\begin{tabular}{|c|c|c|}
\hline & $10-90 \%$ & $20-80 \%$ \\
\hline$T_{r}$ & $54 p s$ & $35 p s$ \\
\hline$T_{f}$ & $51 p s$ & $33 p s$ \\
\hline
\end{tabular}

Table 2: Measured transition times at $5 \mathrm{GHz}$ clock frequency. 


\section{CONCLUSION}

A $8.25 \mathrm{GHz}$ static $1 / 2$ frequency divider IC has been designed using a commercially available $0.5 \mu \mathrm{m}$ gate length $\mathrm{GaAs}$ MESFET process with an average $F_{t}$ across the wafer of $F_{t}=22.9 \mathrm{GHz}$. Thus a high $F_{\text {div }} / F_{t}$-ratio of $F_{\text {div }} / F_{t}=0.36$ is obtained, which we ascribe to the utilization of the peaking in $F_{t}$ and $\mathrm{G}_{\mathrm{m}}$. Also very short transition times of $\mathrm{T}_{\mathrm{t}}(20 \%-80 \%)=35 \mathrm{ps}$ are obtained by applying a novel output-driver design, where we use a differential push-pull buffer/amplifier to drive an open drain differential output stage. Power dissipation is $740 \mathrm{~mW}$, and the output voltage swing is just above $800 \mathrm{mV}$ below toggle frequencies of $7.5 \mathrm{GHz}$ decreasing to $480 \mathrm{mV}$ at the maximum toggle frequency of $8.25 \mathrm{GHz}$.

\section{REFERENCES}

1 Enoki T., Sugitani S. and Yamane Y.:'0.15 $\mu \mathrm{m}$ GaAs MESFETs applied to Ultrahigh-Speed Static Frequency Dividers', Electronic Lett.,1989,Vol.25, No.8,pp.512-513.

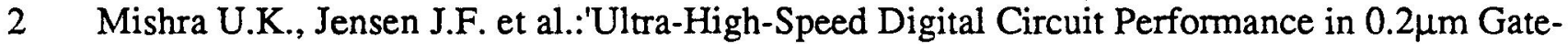
Length AlInAs/GaInAs HEMT Technology', IEEE Electronic Device Letters, 1988, Vol.9, No.9, pp.482-484.

3 Yamauchi Y. et al.:'A 34.8 GHz Static Divider using AlGaAs/GaAs HBTs', Technical Digest, GaAs IC Symposium, San Diego CA.,October 1989, pp.121-124.

4 Rein H.M.:'Multi-Gigabit-Per-Second silicon bipolar IC's for future optical-fiber transmission systems', IEEE Journal of Solid-State Circuits, Vol.23, No.3, June 1988, pp.664-675.

5 Tanaka K. et al.:'High Speed 8:1 Multiplexer and 1:8 Demultiplexer ICs using GaAs DCFL Circuit', Technical Digest, GaAs IC Symposium, Monterey CA, October 20-23 1991, pp.229232.

6 Ohhata M. et al.:'13 Gb/s D-Type Flip-Flop IC using GaAs MESFETs', Electronic Letters, Vol.26, No.14, July 1990, pp.1039-1040.

7 Ohhata M. et al.:'Above 8-Gb/s GaAs Monolithic Flip-Flop ICs for very high-speed optical transmission systems', Technical Digest, GaAs IC Symposium, October 1988, pp.23-26. 